\title{
Beyond Content: The Role of STEM Disciplines, Real-World Problems, 21st Century Skills, and STEM Careers within Science Teachers' Conceptions of Integrated STEM Education
}

\author{
Emily Anna Dare ${ }^{1, *(\mathbb{D}, \text { Khomson Keratithamkul }}{ }^{2}$, Benny Mart Hiwatig ${ }^{2}{ }^{\mathbb{D}}$ and Feng Li ${ }^{1}$ \\ 1 Department of Teaching and Learning, Florida International University, Miami, FL 33032, USA; fli003@fiu.edu \\ 2 Department of Curriculum and Instruction, University of Minnesota, Minneapolis, MN 55455, USA; \\ kerat001@umn.edu (K.K.); hiwat001@umn.edu (B.M.H.) \\ * Correspondence: edare@fiu.edu
}

Citation: Dare, E.A.; Keratithamkul, K.; Hiwatig, B.M.; Li, F. Beyond Content: The Role of STEM Disciplines, Real-World Problems, 21st Century Skills, and STEM Careers within Science Teachers' Conceptions of Integrated STEM Education. Educ. Sci. 2021, 11, 737. https://doi.org/10.3390/ educsci11110737

Academic Editors: Andrea Burrows and Mike Borowczak

Received: 11 October 2021

Accepted: 8 November 2021

Published: 16 November 2021

Publisher's Note: MDPI stays neutral with regard to jurisdictional claims in published maps and institutional affiliations.

Copyright: () 2021 by the authors. Licensee MDPI, Basel, Switzerland. This article is an open access article distributed under the terms and conditions of the Creative Commons Attribution (CC BY) license (https:// creativecommons.org/licenses/by/ $4.0 /)$.

\begin{abstract}
Understanding teachers' conceptions surrounding integrated STEM education is vital to the successful implementation of integrated STEM curricula in K-12 classrooms. Of particular interest is understanding how teachers conceptualize the role of the STEM disciplines within their integrated STEM teaching. Further, despite knowing that content-agnostic characteristics of integrated STEM education are important, little is known about how teachers conceptualize the real-world problems, 21st century skills, and the promotion of STEM careers in their integrated STEM instruction. This study used an exploratory case study design to investigate conceptions of $19 \mathrm{~K}-12$ science teachers after participating in an integrated STEM-focused professional development and implementing integrated STEM lessons into their classrooms. Our findings show that all teacher participants viewed STEM education from an integrative perspective that fosters the development of 21st century skills, using real-world problems to motivate students. Our findings also reveal that teachers have varying ideas related to the STEM disciplines within integrated STEM instruction, which could assist teacher educators in preparing high-quality professional development experiences. Findings related to real-world problems, 21st century skills, and STEM careers provide a window into how to best support teachers to include these characteristics into their teaching more explicitly.
\end{abstract}

Keywords: STEM education; professional development; qualitative; case study; teacher conceptions

\section{Introduction}

Over the past few decades, K-12 education has seen an increased focus on teaching science, technology, engineering, and mathematics (STEM) to prepare students to meet the needs of today's society. In some countries, this focus has been targeted towards an integrated approach to teaching the STEM disciplines, often referred to as integrated STEM education. In the United States, A Framework for K-12 Science Education [1] and the Next Generation Science Standards [2] explicitly call for the inclusion of engineering, along with mathematical and computational thinking as part of science and engineering practices, into $\mathrm{K}-12$ science education. This inclusion of engineering and an awareness of the intimate relationship among STEM disciplines signifies a shift towards more application-oriented settings of science that provide relevant contexts inspired by real-world problems and an emphasis on developing 21st century skills [1], a set of skills that help individuals meet the needs of our increasingly technological society. This type of integrated STEM learning has the potential to increase students' interest and motivation in learning STEM concepts and practices, better positioning them to consider a future STEM career [3,4].

Unfortunately, research that attends to these concerns related to student outcomes may not be fruitful until the education community better understands the nature of STEM integration within K-12 classrooms. Adding to this complexity, there is a distinct lack of consensus surrounding how STEM is conceptualized among stakeholders [5-9], making it 
challenging for teachers to know what to do in their classrooms and for teacher educators to know how to support teachers' professional learning [10-12]. Although certain characteristics of STEM education are shared within the broader community, such as the need to include authentic real-world problems, help students develop 21st century skills, and promote STEM careers [1,13-15], others are less well-defined. For instance, although most of the literature agrees that at minimum, two disciplines should be present, determining the exact nature of integration has been a challenge, as there are "difference[s] in how scholars conceptualize the role of each discipline" [14] (p. 4). In short, there is still debate over how many disciplines are required in order to label instruction as "integrated STEM", and the presence, priority, and role of each discipline varies depending on who you ask [11,14]. Similarly, despite agreement about the need to include content-agnostic aspects such as real-world problems, 21st century skills, and STEM careers $[9,10,13]$, there is a lack of research that explores how teachers conceptualize these components within their instruction. Although some, such as Bybee [7] and Breiner and colleagues [6] caution against having one definition for STEM education, there is a need to refine what it looks like in K-12 classrooms to help teacher educators better design professional learning opportunities to support those interested in implementing integrated STEM education.

Issues concerning the variety of conceptions surrounding the nature of STEM integration highlight the complexity of teachers' own conceptions of STEM and their implementation of such teaching practice. Because teachers' conceptions play a role in their teaching practice $[16,17]$, there is much to learn about teachers' conceptions of integrated STEM to make sense of the instructional decisions they make in the classroom and to better support their work. As such, the purpose of this study is to examine teachers' conceptions related to specific components. As noted above, the literature agrees that multiple disciplines are required, but determining how teachers conceptualize the role of each discipline and the connections between them has yet to be explored in depth. Similarly, the literature agrees that real-world problems, 21st century skills, and promoting STEM careers are important for student learning in integrated STEM education, but it is unclear how these content-agnostic characteristics are conceptualized by teachers; prior research only points to teachers' acknowledgement that they are important to include [10]. Given the uncertainty surrounding conceptions of STEM integration related to these areas, this study sought to address the following research questions: (1) How do teachers conceptualize the role of science, technology, engineering, and mathematics within integrated STEM education? and (2) In what ways do teachers conceptualize real-world problems, 21st century skills, and promotion of STEM career awareness within integrated STEM instruction?

\subsection{Literature Review}

\subsubsection{Teacher Conceptions of STEM Education}

The lack of a clear definition of STEM education is unsurprisingly reflected in the abundance of K-12 teachers' conceptions of STEM education $[9,11,12,18]$. Although variations exist, we [5] found that science teachers preferred models that address the interconnection of STEM disciplines, are science-centric, and allow students to make connections between what they do in school and what happens in the "real-world". One common theme in K-12 spaces is that the term "STEM education" equates to "integrated STEM education" $[5,18]$. It is also clear that K-12 teachers recognize STEM education as more than teaching multiple disciplines simultaneously, even if pre- and in-service teachers struggle to articulate how many disciplines are needed [11] or neglect to describe how it should be enacted in the classroom [12]. These problems reflect those found across different definitions and conceptual frameworks for STEM [14].

Currently, professional development opportunities related to integrated STEM education are limited and include wide variations in how integrated STEM instruction is promoted [19]. However, the literature has noted the importance of professional development in helping teachers develop and refine their own conceptions of STEM education and transform their practice towards a more integrated approach [10,18,20-23]. Du and 
colleagues [21] noted the positive effect professional development had on teachers' perceptions of STEM education, which also made them aware of what support they needed for implementation. After participating in a year-long professional development experience, Wang and colleagues [24] found that teachers from different disciplines held various conceptions of STEM education, which was reflected in their practice. Similarly, we [10] found that after participating in professional development, teachers' conceptions of STEM education translated directly into their written curriculum. This included conceptions related to the degree of integration, such as connecting the disciplines, balancing science and engineering, and science- or engineering-focused. Although this work did not explore the role of each STEM discipline explicitly, these themes elucidate the fact that teachers make some decisions related to the role of each discipline. This is most prominently reflected in the finding that teachers often positioned mathematics and technology as tools/supports in STEM $[10,18]$.

What is important to emphasize within these few studies examining teachers' conceptions of integrated STEM is that the shift towards some model of integrated STEM instruction goes beyond content integration. For example, in addition to the themes mentioned above, we [10] noted two content-agnostic aspects within their conceptions and written curriculum related to the importance of including 21st century skills and connections to the real-world. This emphasis on the inclusion of 21st century skills and connections to the real-world includes opportunities for students to learn about STEM careers $[5,10]$. It is these components of STEM education that allow teachers to focus on preparing their students for future success by arming them with the necessary skills [9]. However, in-depth exploration of these areas within integrated STEM teaching and learning has not been the focus of much research. Exploration in these areas is needed to better understand the needs of teachers and students as they engage in integrated STEM teaching and learning.

\subsubsection{Beyond Content in Integrated STEM Education}

The literature related to STEM education consistently includes several characteristics that differentiate integrated STEM from a more traditional teaching approach: real-world problems, 21st century skills, and STEM careers $[1,14,15]$. First, the use of real-world problems reflects the need to increase diversity in STEM fields [25,26]. Engaging students in developing solutions to real-world problems helps to motivate and contextualize learning [27], while also allowing students to draw from their knowledge of multiple STEM disciplines [28]. These problems should connect to students' lives to enhance engagement and increase the relevance of learning [29-31]. While the use of real-world problems is included in the literature as important, and previous research has noted teachers' awareness of this need $[5,10]$, it is yet unknown how teachers approach this aspect in their conceptions and practice.

Second, one of the main goals of K-12 STEM education is to support learners' development of skills needed to succeed in their pursuit of STEM careers and in their adult lives $[1,32,33]$. These skills have been commonly referred to as 21 st century skills, which are sought after by employer [4] and play an essential role in meeting the goals of integrated STEM education [33-36]. With rapid advancements in technology and globalization, future STEM professionals need to be adept in critical thinking and creativity to solve problems, be able to work productively in teams, and communicate effectively $[33,37,38]$. Communication, collaboration, creativity, and critical thinking (the 4-Cs) are deemed as core 21st century skills for higher education, the job market, and society in general [33] (Table 1). They are also seen as vital skills needed in innovation and design-focused environments [39]. The 4-Cs empower students to search, learn, and apply content knowledge to solve problems, which are crucial skills for young learners [40]. Despite agreement that these skills are pivotal for students' success, it is unclear how these skills fit into teachers' conceptions of integrated STEM education. 
Table 1. Description of the 4-Cs.

\begin{tabular}{c} 
Short Description \\
\hline Critical Thinking \\
Critical thinking is the ability to look for evidence to support \\
claims and beliefs [41] and ask and answer critical questions \\
[42]. It encompasses effective reasoning, systems thinking, \\
making judgments and decisions, and problem solving [39]. \\
Creativity is a multifaceted skill [43] that leads to innovation \\
and effective problem solving. It comprises generation of \\
multiple ideas and solutions to problems and making \\
associations between remote concepts [44]. \\
Collaboration is an essential skill in problem solving and the \\
construction of knowledge. It is manifested when members \\
communicate with each other, reflect as a group, make \\
decisions collectively, build trust, manage conflicts, \\
maximize collective knowledge, and take turns assuming \\
leadership roles [45,46]. \\
Communication comprises information delivery, \\
interpersonal skills, interactive communication, and even \\
teamwork, among others [47]. With the emergence of new \\
technologies, communication becomes coupled with the \\
increased use of information and communications \\
technology (ICT) that allows learners to acquire information \\
more efficiently, communicate faster and more effectively, \\
and maximize learning, overall [48].
\end{tabular}

Finally, the inclusion of 21st century skills within integrated STEM education connects what happens during instruction to the types of practices and skills used by STEM professionals. This is one way to help introduce students to STEM careers and potentially increase diversity within STEM fields $[1,37,49]$. Since teachers play an important role in shaping students' perceptions of and introducing students to actual STEM professionals [50,51], introducing STEM careers can be done by making explicit connections to and promoting awareness of STEM careers. This can empower students to pursue careers in STEM and fill the increasing societal need for STEM workers [1], especially in terms of increasing historically marginalized students' engagement and interests in STEM [26,52-54]. Integrated STEM education, then, can be a means for historically underrepresented students in STEM to push back against social injustices. However, little is known about how teachers conceptualize or accomplish this in their integrated STEM teaching. Some note that this may be challenging for teachers who have little knowledge of STEM careers [55], and that they could benefit from professional development that includes STEM professionals as guest speakers [56].

Because little is known about the specifics of teachers' conceptions of integrated STEM education with respect to areas such as real-world problems, 21st century skills, and STEM career awareness, there is a need to conduct research in this area. It is clear that these components are valuable to teachers $[5,10]$, but better understanding how they frame these components in the broader context of their conceptions of integrated STEM education may help teacher educators better support them in their professional learning. What is clear is that teaching integrated STEM is more than just teaching multiple disciplines, but research related to teachers' conceptions must go beyond counting disciplines to better examine the nature of disciplinary relationships and exploring critical content-agnostic characteristics of integrated STEM education.

\section{Materials and Methods}

\subsection{Research Design}

This study utilizes an exploratory case study design $[57,58]$ to explore teachers' conceptions of integrated STEM education, focusing on the role of each STEM discipline and 
how real-world problems, 21st century skills, and STEM careers fit into their conceptions of STEM education. This choice of design reflects the need to study a phenomenon that is underexplored $[57,58]$. As noted above, there are limitations in the research community's understanding of the role of STEM disciplines within conceptions of STEM education. To our knowledge, none of the studies have attended in detail to the specifics of conceptions of each STEM discipline and other aspects of integrated STEM education that go beyond an examination of disciplinary content.

\subsection{Conceptual Framework}

The work presented here was conducted as part of a larger project that required the development of a new conceptual framework for integrated STEM education. It focuses on practical characteristics to be included as part of K-12 integrated STEM curricula and practice [13]. We initially drew from the broad definition provided by Kelley and Knowles [59] wherein STEM education is "the approach to teaching the STEM content of two or more STEM domains, bound by STEM practices within an authentic context for the purpose of connecting these subjects to enhance student learning" (p. 3). We expand upon this definition to include seven central characteristics that should be incorporated as part of K-12 integrated STEM curricula and practice: (1) engineering design, (2) real-world problems, (3) context integration, (4) content integration, (5) authentic STEM practices, (6) 21st century skills, and (7) STEM career awareness [13]. This particular conceptual framework is grounded in the notion that integrated STEM education is more than presenting students with content from multiple disciplines. Rather, it presents such content in a way that authentically represents the work of STEM professionals. Of particular importance is the emphasis on engineering design, which is contextualized by a real-world problem and engages students in the use of authentic STEM practices and 21st century skills. Above all else, this framework of integrated STEM is geared towards the inclusion of a diverse group of students and calls for explicit connections to both students' lives and STEM careers.

\subsection{Study Context and Participants}

The boundary of this case study is three 1-week professional development (PD) workshops focused on integrated STEM education offered to K-12 science teachers [60]; one of these workshops took place in an urban Southeast region of the United States and the other two workshops took place at the same site in the Midwest (separated by elementary and secondary teachers). These workshops provided teachers with a foundational knowledge of integrated STEM education as defined by our conceptual framework [13], examples of integrated STEM activities, lessons, and units, and dedicated time to modify or develop their own curriculum materials for classroom use. All workshops included a series of activities to elicit and support the development of teachers' conceptions of integrated STEM education [60]. On the first day, teachers sketched out their conceptions of STEM education, which provided a visual tool from which they could work; this visual was meant to encourage reflection of teachers' conceptions of STEM, including opportunities to refine their conceptions. While the full details of these activities can be found in [60], Table 2 provides a summary.

It is important to note that a prescriptive set of guidelines related to integrated STEM education was not shared with the teachers to encourage them to develop their own understanding that would work within their school context. This is especially important given that "PD programs have the best chance of impact on teacher and student outcomes when the goals of the PD program are aligned with policies at the school, district, and state levels, as well as existing teacher beliefs regarding STEM" [22] (p. 204). Rather than sharing a strict set of guidelines or a step-by-step recipe for implementing integrated STEM education, we presented integrated STEM education as four categories with a total of 13 elements (see Figure 1). These elements arose out of the conceptual framework [13], but it should be noted that one category (STEM pedagogies) was viewed as separate from the conceptual framework as it focused on quality of good teaching practice. Each of 
the sample integrated STEM activities was designed to highlight one or more of these elements. After teachers completed an activity as a student would, they engaged in prompted reflective discussions related to the targeted elements. The purpose of these discussions was to help teachers better understand and internalize these elements for inclusion in their own curriculum materials they were working on. After participating in the workshops, teachers were expected to implement their own lessons or lessons shared in the PD in their classrooms the following school year, during which a member of the project team observed and video-recorded the lesson(s).

Table 2. Summary of professional development workshop activities related to eliciting teachers' conceptions of STEM education [60].

Day 1: Eliciting STEM Conceptions

Day 1: Sharing STEM Conceptions

Day 1: The Role of S, T, E, and M
All teachers were asked to draw a model of STEM education that best represents how they currently understand STEM education.

Teachers met in small teams to discuss their models and then met as a large group to discuss if they would make changes to their model based on what they saw.

Teachers worked in small teams to consider the role of science, technology, engineering, and mathematics, using small sticky notes to describe the role of each in integrated STEM. These small sticky notes were then placed on large poster paper corresponding to each discipline and grouped by the teachers.

Similar to Day 1, all teachers were asked to draw a model of STEM education that best represents their current understanding of STEM education.

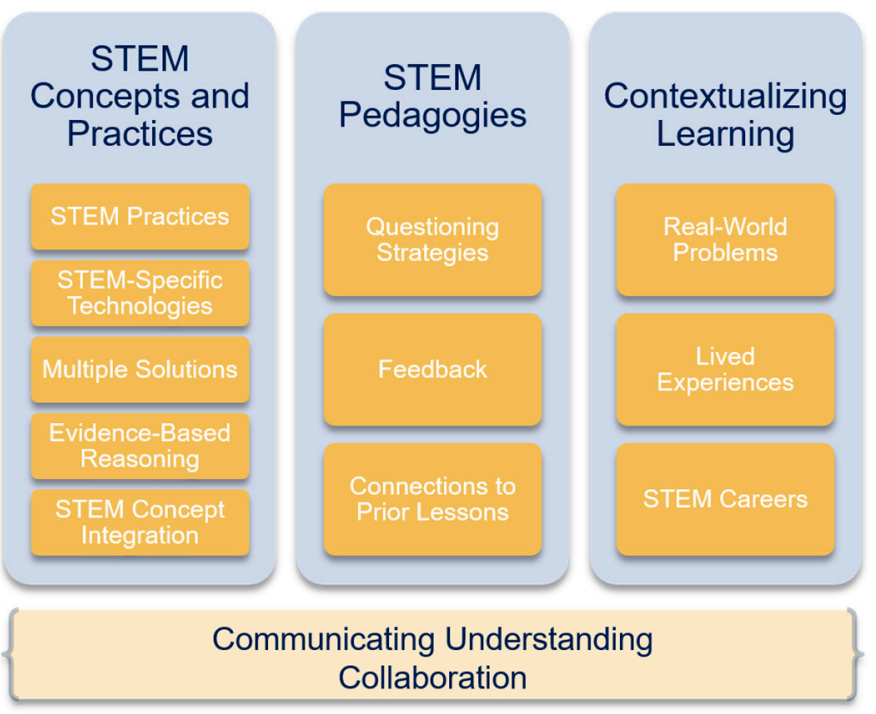

Figure 1. Visual map of integrated STEM education used in professional development [60].

A total of 106 elementary, middle, and high school teachers participated in the three workshops. Although interviews were planned with all teachers as part of their participation in the overall project, the abrupt shift to remote teaching as a result of the COVID-19 pandemic hindered our ability to interview all participants. Instead, teachers were recruited to participate via email requests sent out by the research team. This resulted in 17 secondary science teachers (10 high school and seven middle school) and two general 
elementary teachers agreeing to participate in interviews (Table 3). All participants modified or designed their own integrated STEM lesson(s) and had implemented at least one integrated STEM lesson in the 2019-2020 academic year prior to US schools transitioning to remote teaching.

Table 3. Teacher participants.

\begin{tabular}{ccc}
\hline Site & Grade Band & $\begin{array}{c}\text { Teacher Names } \\
\text { (Pseudonyms) }\end{array}$ \\
\hline Site 1 & High School & $\begin{array}{c}\text { Antonio (Physics), Christine (Biology), } \\
\text { Jason (Marine biology, Physical science), } \\
\text { Jocelyn (Biology), Liliana (Chemistry) }\end{array}$ \\
\cline { 2 - 3 } & Middle School & $\begin{array}{c}\text { Clara, Darma, Edith, Pablo, Rose (all } \\
\text { general science) }\end{array}$ \\
\hline Site 2 & High School & $\begin{array}{c}\text { John (Physics), Elijah (Chemistry), Kyle } \\
\text { (Physical science), Stacey (Environmental } \\
\text { science), Tim (Physical science) }\end{array}$ \\
\cline { 2 - 3 } & Middle School & Alina, Mike (all general science) \\
\hline Elementary & $\begin{array}{c}\text { Macy (3rd-5th grade), Marianna (5th } \\
\text { grade) (all general elementary) }\end{array}$ \\
\hline
\end{tabular}

\subsection{Data Collection and Analysis}

Each interview took place via video conferencing, was recorded, and typically lasted 45-60 min. Prior to their interview, participants were asked to draw their current conception of STEM education and email it to the interviewer ahead of time. The purposes were to "prime" the teachers for the interview and to provide the interviewer with a point of reference. The interview protocol was organized to elicit teachers' conceptions surrounding integrated STEM education as a whole, the role or purpose of each STEM discipline within integrated STEM education, how real-world problems fit into in their conceptions, how 21st century skills were included in their conceptions and teaching, and how teachers conceptualized promoting STEM career awareness in their classrooms. These interviews were not designed to measure the effect or impact of the PD on teachers, but rather to explore teachers' conceptions after having implemented one or more integrated STEM lessons in their classrooms.

All interviews were transcribed verbatim prior to coding and analysis. The fourmember research team first selected one transcribed interview to create a list of provisional codes as part of preliminary analysis [61]. Coding focused on teachers' overall conception of STEM education, the role of each STEM discipline, the inclusion of real-world problems, the role of 21st century skills, and the promotion of STEM career awareness. After individually coding this selected interview and discussing codes as a group, the team refined the utilized codes and created a codebook. With a second pass through the same interview, all researchers used the codebook to recode the transcript. After a second discussion in which consensus was reached on codes and code placements, the codes were refined before coding additional transcripts. Each researcher coded all transcripts, adding additional codes as needed. Credibility and confirmability of these codes were established through coming to consensus through discussion. Once all transcripts had been coded and discussed, we grouped and organized the codes in a table to facilitate collapsing of the codes where similar codes overlapped. This visual display of codes allowed us to identify patterns across the interviews using thematic analysis [62]. This helped us focus on key features that aligned with our research questions. In looking across these patterns, we identified themes across our pre-selected categories (i.e., the research questions) that were common across teachers' shared conceptions, which are described in the findings below. 


\section{Results}

\subsection{Overall Conception of Integrated STEM Education}

We first examined teachers' overall conceptions of integrated STEM education to assess if this group of teachers' conceptions aligned to what previous research has found. In doing so, we identified five major themes: interconnection between disciplines, student-centered pedagogy, development of 21st century skills, STEM for all, and relevant and based in the real-world. These themes are described in Table 4, alongside sample quotes from teacher participants, and were determined to be consistent with the literature $[5,10,14,18]$. This initial analysis helped us to confirm that, in general, teachers' overall conceptions of STEM were consistent with previous findings, but our focused work dug deeper into the various elements of integrated STEM education.

Table 4. Summary of overall conceptions of integrated STEM education.

\begin{tabular}{|c|c|c|}
\hline Theme & Brief Description & Example Quote \\
\hline $\begin{array}{l}\text { Interconnection between } \\
\text { disciplines }\end{array}$ & $\begin{array}{l}\text { An interconnection between } \\
\text { STEM disciplines wherein the } \\
\text { number of STEM disciplines } \\
\text { are fluid and dynamic. When } \\
\text { multiple disciplines are } \\
\text { present, they should be } \\
\text { connected in some way. }\end{array}$ & $\begin{array}{l}\text { "kind of like a circle where } \\
\text { we're going to be including all } \\
\text { of this [STEM] all of the time } \\
\text { or portions of this [STEM] } \\
\text { some of the time". (Clara) }\end{array}$ \\
\hline Student-centered pedagogy & $\begin{array}{l}\text { Includes hand-on activities } \\
\text { that could resemble } \\
\text { project-based learning, which } \\
\text { engages and excites students } \\
\text { to learn STEM content. }\end{array}$ & $\begin{array}{l}\text { "It's a way to implement steps } \\
\text { you take, you know...some } \\
\text { science and engineering. And } \\
\text { then you come up with a } \\
\text { project based on that. Or you } \\
\text { take some math and you take } \\
\text { some technology and you } \\
\text { make a project based on that". } \\
\text { (Mike) }\end{array}$ \\
\hline $\begin{array}{l}\text { Development of important } \\
\text { skills }\end{array}$ & $\begin{array}{l}\text { Integrated STEM education is } \\
\text { a vehicle by which students } \\
\text { could develop important } \\
\text { skills in preparation for future } \\
\text { success. These skills transcend } \\
\text { different disciplines, including } \\
\text { non-STEM disciplines. }\end{array}$ & $\begin{array}{l}\text { "a good, strong, integrated } \\
\text { STEM unit would be } \\
\text { developing those, those skills, } \\
\text { those life skills, um, for } \\
\text { students, um, whether or not } \\
\text { they go into the STEM field or } \\
\text { not". (Stacy) }\end{array}$ \\
\hline
\end{tabular}

Integrated STEM should encourage and improve minoritized students' access

STEM for all to integrated STEM, including those from underrepresented racial and ethnic groups, women, and students with cognitive disabilities.

Relevant and based in the real-world
Integrated STEM education should utilize relevant and real-word problems that students can relate to. This should also allow students to connect between what they do in school with what STEM professionals do.
"You want to make sure that they are inclusive to all our learning disabled, our English language learners, our gifted". (Clara)

"You need to be more purposeful when you're designing what you're doing to make it, that the kids are actually doing the things that they do in STEM and being scientists and engineers". (Kyle)

"That is the most important thing, is that solving problems that is relevant to real world issues". (Elijah) 


\subsection{Conceptualizing the Role of $S, T, E$, and $M$ in Integrated STEM Education}

We specifically asked teachers about the role of each STEM discipline within their conception of integrated STEM education, allowing them an opportunity to expand upon their overall conceptions. The sections below attend to this, summarized in Table 5 . Included in these findings is our interpretation of how teachers positioned each discipline in relation to the others.

Table 5. Summary of themes describing the role of each STEM discipline.

\begin{tabular}{|c|c|}
\hline Discipline & Themes \\
\hline Science & $\begin{array}{ll} & \text { Epistemological construct } \\
\text { - } & \text { A central feature in STEM } \\
\text { - } & \text { Relationship of science to other STEM disciplines }\end{array}$ \\
\hline Technology & $\begin{array}{ll}\text { - } & \text { Tools to engage in STEM } \\
\text { - } & \text { Digital tools } \\
\text { - } & \text { A product of engineering } \\
\text { - } & \text { Relationship of technology to other STEM disciplines }\end{array}$ \\
\hline Engineering & $\begin{array}{ll}- & \text { Design-focused } \\
\text { - } & \text { Solving problems } \\
\text { - } & \text { Relationship of engineering to other STEM disciplines }\end{array}$ \\
\hline Mathematics & $\begin{array}{ll}\text { - } & \text { Tools and practices } \\
\text { - } & \text { Epistemological construct } \\
\text { - } & \text { Relationship of mathematics to other STEM disciplines }\end{array}$ \\
\hline
\end{tabular}

\subsubsection{The Role of Science in Integrated STEM Education}

Teacher's conceptions of science within integrated STME education focused on: (1) science as an epistemological construct and (2) science as central.

\section{Epistemological Construct}

Teacher participants described science as a body of knowledge to understand the world, a means to explore natural phenomena, or a discipline devoid of human input. For instance, Kyle mentioned that in science "we study the natural world, try to figure out how things work out there, have questions, do experiments to answer", supporting the idea that science is a means to explore natural phenomena through asking questions and conducting experiments. Stacy further noted, "...science being kind of the, the knowledge, the understanding of how the world works". This role of science as a body of knowledge and a way to learn about the world reflects positivist notions that science has correct answers.

\section{A Central Feature in STEM}

Teachers also described science as central to integrated STEM education and that without it, integrated STEM education would not exist. Subsequently, several teachers noted how science standards were the driver for STEM curricula. For instance, Kyle noted, "The science we learn-engineers can use those concepts into what they're making, designing, building, problem solving". Similarly, Stacy described how her integrated STEM unit planning begins with science before finding an appropriate engineering design challenge, centralizing the role of scientific content. Kyle even highlighted the importance of science beyond simply pursuing a science-related career, stating, "science opens lots of doors out there in the world". It is clear that teachers prioritized science in their understanding of integrated STEM education, which is not surprising given their position as science teachers.

\section{Relationship of Science to Other STEM Disciplines}

Teachers' positioning of science as their "starting place" when conceptualizing integrated STEM education reflects previous findings [10,19]. As science teachers, their perceived responsibility was in assuring that content was learned and standards were 
met. Beyond this, teachers noted the process of scientific discovery to understand the natural world, and suggests that that knowledge gained could be used by engineers to solve problems. In this vein, it appears that teachers readily saw connections between science and engineering, with only one teacher (Darma) commenting on the inseparable nature of science and mathematics.

\subsubsection{The Role of Technology in STEM Education}

Teacher participants described technology's role in STEM education in multiple ways. While not mutually exclusive, we identified three themes: (1) technology as tools to engage in STEM, (2) technology as digital tools, and (3) technology as a product of engineering.

\section{Tools to Engage in STEM}

Technology was most commonly discussed by teachers as a tool used to "do STEM" (i.e., tools used by students to complete tasks) or to teach STEM (i.e., tools for pedagogy). Some teachers considered technology as tools and equipment to facilitate engagement in STEM practices such as data collection, representation, and analysis, affording students the ability to engage in STEM learning by engaging in (or "doing") STEM practices. Stacy mentioned probeware (e.g., Vernier equipment) as an example of technology used in monitoring water in one of her STEM activities, noting "technology-I see as the tools, the things that we use, um, hopefully to make our lives a little bit easier". Teachers also described technology as tools for pedagogy, often as a means of communication among students. For instance, Allina saw technology as tools that "make it easier to share data. It [technology] makes it easier to analyze data. It [technology] makes it easier to collaborate". Further, Liliana emoted the complexity of technology, "a technology is not only for the presentation of the research. They [students] can also use it to create things, they can actually try to find ways to solve problems and create things with technology tools that they have available". The duality of engaging students either through their direct use of technology or through the teacher's pedagogical choices was seen as positive in nature as it facilitated students' accomplishment of tasks, which could not be done without the technology.

\section{Digital Tools}

In describing technology, more than half (11 out of 19) of the teachers described technology only in digital forms. In particular, Clara talked about her use of iPads to present course material, but also as a tool for students to develop and present their engineering designs. Likewise, Jocelyn mentioned digital spreadsheets as an example of technology that students used to organize and analyze data. While acknowledging the benefits of technology, teachers such as Jocelyn, Clara, Pablo, and Mike pointed out negative effects, with Mike stating, "I think there's a big danger in that it could be a distraction. You've got technology for technology's sake, it's not really helping anybody, but it sure looks cool". This focus on digital technology was sometimes viewed as a negative factor when it came to student learning. For example, Clara mentioned students being overly reliant on online tools to search for answers to problems, preventing students from exploring the questions and solving problems by themselves. She mentioned that "this quick access of getting answers [via technology] has caused them to be a little lazy". Some tension about the use of digital technology appears to exist within teachers' conceptions

\section{A Product of Engineering}

Five teachers explicitly described technology as the product of engineering, noting the connection between what is done within the engineering field and the tools that students use in class. Stacy noted, "That line between technology and engineering is very fuzzy because you're engineering a new technology". She expanded this by noting, "You know, scientists need a new technology to be able to find a new way to measure something or they need to invent something so that they can measure it". This can be thought of as a cyclical 
understanding of technology such that there are multiple access points for technology usage in the classroom.

\section{Relationship of Technology to Other STEM Disciplines}

Even though most teachers described technology as tools to engage in STEM learning, this could not be fully separated from the idea that technology is something akin to the binding agent between the other disciplines. This is made clear by Mike who shared, "so the technology piece is a little bit of the glue that brings a lot of those...have the science, the engineering, and the math together". Rose also considered technology as the "key" to STEM toward creating "more effective solutions" to engineering problems. Stacy's comments above about technology being a product of engineering demonstrates her belief that technology is an inherent part of science and engineering; further, this relationship is bidirectional. Although mathematics was not called out directly, teachers noted the importance of technology in performing tasks such as organizing and analyzing data.

\subsubsection{The Role of Engineering in STEM Education}

Teachers' views of engineering within STEM education spanned two broad themes, which were not mutually exclusive from one another: (1) design-focused and (2) solving problems.

\section{Design-Focused}

All but five teachers focused their conceptions of engineering on the engineering design process. They described engineering as a cyclical, iterative design process used in the development of products or solutions to real-world problems or design challenges. According to Clara, this included "re-visiting original designs, fine-tuning them, going back, testing, and then making adjustments accordingly". For Jason, engineering is "the process that they [students] have to use when they're performing the tasks with the plan, design, model, test, evaluate, redesign, so forth". Teachers such as Antonio noted the similarity between the scientific method and engineering, "It's like a basic scientific method. All the steps. If you decide it's not effective, you have to redesign it and that's it-that is the way to do it". Within this focus on the design process, teachers were conscious of including evaluation and redesign.

\section{Solving Problems}

In addition to the focus on the steps of the engineering design process, teachers described engineering as a context or vehicle to solve problems or develop products; this included general problem solving and solving contextualized, real-world problems. For instance, Kyle noted, "I think what engineers do is more of a problem solving-like, you're given, 'I need to accomplish this. How can we do it?'" Marianne noted that her students "understood the difference between the scientific method and the purpose of that- to answer questions... and engineering to come up with something to solve a problem". Macy also noted the connection between designing and problem solving where her students "look at designs, improve designs, and use what they have already learned and what they know from previous experiences to improve or be able to solve their problems better".

\section{Relationship of Engineering to Other STEM Disciplines}

The relationship between engineering and other STEM disciplines appeared to vary across teacher participants. Some conceptualized the role of engineering as both the creation of technology and application of scientific knowledge; for example, "engineers invent technology to do science" (Stacy) and that the "engineering design process goes hand in hand with science" (Clara). Engineering was also described as the integrator to provide a context to learn STEM content through a real-world problem, a theme that cuts across the previously mentioned themes related to engineering. Three biology teachers (Jason, Christine, and Jocelyn) noted the importance of engineering in integrated STEM education, 
but noted the challenges within biology courses due to cost and time. This relationship between engineering and the other disciplines was made the clearest with respect to science and technology; notably the connection to mathematics was not vocalized.

\subsubsection{The Role of Mathematics in STEM Education}

When asked to describe the role of mathematics within integrated STEM education, teachers' responses covered two related themes: (1) mathematics as tools and practices and (2) mathematics as an epistemological construct.

Tools and Practices

Similar to technology, mathematics was typically viewed as a set of tools or practices used to "do STEM". An overwhelming fourteen teachers viewed mathematics as a set of practices related to data analysis to answer scientific questions and/or to test engineering designs. Stacy noted how mathematics allows scientists to do their work, stating, "Newton's a perfect example of how the math and the science came together to be able to describe the world and how objects move with gravity. He needed to invent calculus to better describe mathematically his scientific principles". Mathematics as data analysis was described by Tim as, "you know math and data analysis and graphing and making decisions based on data is essential to STEM". Eleven teachers described mathematics as a set of tools. Liliana explained, "You need math for every calculation. So they need math for the formulas, they need math for the experiments". Jocelyn described how she and her students used math "to ultimately perform the engineering" through "working on statistics" using spreadsheets. She also related how her students "get the conceptual idea in their math class, but in the science world they're actually learning how to put formulas into spreadsheets or how to use math to describe populations and using math as a tool to describe patterns". As part of this, mathematics was described as data representational tools mostly through data graphing and visualization. Rose shared how, in her lessons, "the math part was the graphs, interpreting the graphs". It is clear that mathematics plays a vital role in integrated STEM instruction, especially when it comes to data analysis.

\section{Epistemological Construct}

Six teachers viewed mathematics as a body of knowledge within STEM education and provided examples of mathematics content knowledge used in their integrated STEM lessons, moving away from a vision of mathematics as primarily data analysis. For example, Rose described how she taught students to use the concept of ratio in their budget calculation for an integrated STEM project. As alluded to above, teachers also viewed mathematics as essential to integrated STEM, especially with respect to science, as students needed to be math literate. Simultaneous to with this, five teachers viewed mathematics as a barrier such that they viewed their students as lacking necessary mathematics knowledge and skills to solve problems. They described the mathematics within their STEM curricula as the basic knowledge and skills that every student should have, but were lacking. Pablo shared, "I think that the students don't have the background that they need to understand how to present data when they collect data in an experiment," which caused anxiety for him to implement integrated STEM lessons in his classroom. Tim pointed out that his students "don't even have the skills to do some of the stuff that we do on a regular basis with calculations".

\section{Relationship of Mathematics to Other STEM Disciplines}

In considering teachers' responses about the different ways in which mathematics can be used within integrated STEM education, the relationship is quite unclear. However, ten teachers noted how mathematics was central to STEM with Darma noting the critical connection between mathematics and science, "so without math, you can't do science". To some, mathematics was more of a supporting feature-used as tools or a set of practices (e.g., data analysis) - and it was seen by fewer teachers to be an isolated body of knowledge 
or central to STEM. Similar to technology, mathematics appears to be an area of STEM education that is not well-defined for science teachers; however, it should be noted that while the importance of mathematics was clear, its purpose varied.

\subsection{Conceptualizing STEM beyond Content Integration}

In addition to understanding how each STEM discipline is conceptualized within integrated STEM education, we further explored how teachers conceptualized and approached some of the content-agnostic aspects of integrated STEM education-real-world problems, 21st century skills, and promotion of STEM career awareness. By examining these areas, our hope was to better understand how science teachers shift from teaching science to teaching integrated STEM. Table 6 provides an overview of the final themes in each of these areas.

Table 6. Summary of themes describing real-world problems, 21st century skills, and promoting STEM career awareness.

\begin{tabular}{cll}
\hline Aspect of STEM & & \multicolumn{1}{c}{ Themes } \\
\hline Real-World Problems & - & $\begin{array}{l}\text { Real-world problem as context } \\
\text { Relevance of the real-world problem }\end{array}$ \\
& - & 21st century skills are a pedagogical choice \\
21st Century Skills & - & 21st century skills need to be developed \\
& - 21 st century skills relate to technology \\
\hline \multirow{2}{*}{ Promoting STEM Career Awareness } & - & Promotion of STEM careers through curricula \\
& Promotion of STEM careers through partnerships \\
& & Diversity-oriented promotion of STEM careers \\
\hline
\end{tabular}

\subsubsection{Real-World Problems}

Interviews revealed two main themes related to the use of real-world problems within integrated STEM education: (1) real-world problems as context and (2) relevance of the real-world problems. Three teachers noted that they faced challenges in incorporating or choosing appropriate real-world problems into their teaching with one teacher (Rose) noting the importance of needing a partnership to realistically include a real-world problem.

\subsubsection{Real-World Problems as Context}

Nine teachers described how they used real-world problems as a context for their integrated STEM instruction, which, according to Stacy and Allina, could foster long-term learning and deeper understanding of a given topic. Stacy noted, "I think that that comes right at the beginning with the teacher being explicit about "here's a real-world problem that we need to work with". Rose described how her integrated STEM lessons were grounded in real-world problems, describing an activity that involved creating unobtrusive weather stations. In particular, she noted the importance of partnerships to boost the authenticity of the problems, sharing "I believe that partnerships are incredibly important if you're really going to teach the kids to tackle real life problems".

\subsubsection{Relevance of the Real-World Problem}

In some cases, there was an overlap with using a real-world problem as a context for learning, but in other cases, teachers referred to general problems that were relevant to students. For Marianne, she believed that "if you create those real-world experiences, that creates the relevance. That creates the excitement. That creates the empowerment". This was done either by selecting real-world problems directly related to students' lives or to global issues. For example, Edith noted how she wanted her students to make a connection to their local environment for an integrated STEM unit related to recycling, "We took them in the context of the real world. I mean, we live in [our state]. We're surrounded by water. There're lakes. There's the canal. There's the Gulf and there's the Atlantic". Christine described how she connects her biology work with plants to measuring students' carbon 
footprint, making strong connections to issues of global climate change. One particular example that shows this overlap was described by Darma, who discussed a way to bring the current COVID-19 pandemic into play, having her students explore viruses and materials to design and create facemasks. Conceptualizing real-world problems in these relevant ways appeared to motivate these teachers to bring integrated STEM to their students.

\subsubsection{1st Century Skills}

In their overall conceptions, teacher participants described integrated STEM education as a way to help students develop skills for their current and future lives, but these skills were not described in detail until explicitly asked. Within teachers' responses related to 21st century skills, we identified three themes: (1) 21st century skills are a pedagogical choice, (2) 21st century skills need to be developed, and (3) 21st century skills relate to technology.

\subsubsection{1st Century Skills Are a Pedagogical Choice}

Teacher participants viewed 21st century skills as part of their pedagogical choices. This centered primarily on the use of collaborative student groups, while some teachers also incorporated communication. Collaboration and communication were seen as necessary to enhance their use of integrated STEM education such that teachers required students to work in groups and used a variety of tools to encourage student communication of ideas. Elijah described, "We have to monitor and make sure that everybody's input is considered and make sure that everybody is participating". For communication, teachers also required their students to share their learning with others, often through technological affordances (e.g., PowerPoint, Excel). In some cases, such as Jason, communication was expected as an end product. He highlighted how "they [students] also communicate at the end-usually some type of presentation to your classmates". In this sense, both collaboration and communication were viewed as outcomes within a broader conception of integrated STEM education.

\subsubsection{1st Century Skills Need to Be Developed}

Most teacher participants (17 out of 19) additionally noted the 4 Cs as a set of skills that K-12 students need to develop, and they were described as incorporated into typical classroom practice. This was done to provide students with, "tools or skills that they will be able to use not only in high school, but in their future" (Pablo). Although the general consensus was that these $4 \mathrm{Cs}$ need to be developed, each skill was attended to in different ways. Collaboration was commonly noted as a set of skills that could and should be taught explicitly in classrooms. As Stacy noted, "collaboration just doesn't come naturally in a classroom. It needs to be explicitly taught, so much so that I actually have a rubric on teamwork". Teachers also described collaboration as a means to provide students with different perspectives, noting various benefits to working in small groups. Lilliana shared: "Collaboration is extremely important because they [students] learned that when they try to do things by themselves, sometimes they don't find a solution that they want, but when they work together, someone can come up with a different idea, come up with a different approach, and then they can just try to put this together".

Similar to the theme above, developing communication skills in the classroom was often intertwined with collaboration; oddly, those who described communication as pedagogy did not also describe it as a set of skills that need to be developed. Nonetheless, teachers recognized the importance of developing communication skills, citing their observations of miscommunications between students in a group during an integrated STEM lesson. Rose explained: "I remember having a group who had a hard time communicating and you could see it at the end and their prototype. They were fighting over, 'Yo, I want to use this material', 'No, this is better', 'No, this is better'... And again, they were wasting their time because they did not know how to communicate. So that is extremely important". 
Rose went on to describe how some students communicate better with different modes of communication (e.g., email versus oral skills). Curiously, when describing the need for communication when students work in groups, teachers only provided examples of failed communication and did not note what successful communication would look like in their classrooms. These communication skills were also described in the context of STEM professionals with Allina describing how engineering is not just about an end product, but rather about sharing information with others.

Creativity was also described as a set of general skills, but teachers additionally highlighted the importance of creativity in solving problems in particular and as important for future careers in STEM fields and beyond. Twelve teachers described creativity as developing multiple ways to solve problems, which would help students think divergently. Antonio noted, "They have to create their own steps and I don't like to give you steps. They have to be creative. They have to innovate. They have to design". Macy described, "When I was teaching STEM, and really any subject area, I really tried to activate my students' creativity and allow them to come up with their own ideas and build and solve problems using their imagination". Four teachers addressed the importance of creativity in career aspects in particular. They viewed developing creativity for future careers as one of the purposes of integrated STEM education, even for students not pursuing a STEM career. Allina noted that "in order to be a productive part of whatever they do in society-whatever job-they have to be able to innovate".

Of the 4-Cs, developing critical thinking skills was addressed to a lesser extent, although when it was mentioned, teachers related it to problem solving. For example, Mike noted, "I see lots of natural alignments between STEM and critical thinking. It's not just learning so that you can become faster at information and processes. It's more about, you know, we need people to solve problems". This clear, explicit connection that Mike shared addresses how critical thinking is a part of problem solving within integrated STEM education. Six other teachers acknowledged the importance of developing critical thinking skills, but did not provide examples of how this was done in their classrooms.

\subsubsection{1st Century Skills Relate to Technology}

As noted above, teachers often related technology with students' ability to communicate with others, especially as a physical, digital tool (e.g., tablet, laptop). In addition to connections to the 4-Cs as part of 21st century skills, teachers also described other skills beneficial to students, such as technology literacy and digital technological skills (e.g., data analysis and computer programming skills). Teachers were clearly aware of the growing reliance on technology that students would need for their futures, independent of career choice. Teachers such as Clara noted, "We want to make sure that these students are prepared for the 21st century, that they are getting coding-that they're getting the robotics, that they're getting the engineering design principles".

\subsubsection{Promoting STEM Career Awareness}

We identified three themes related to how teachers promoted STEM career awareness in their classrooms: (1) promotion of STEM careers through curricula, (2) promotion of STEM careers through partnerships, and (3) diversity-oriented promotion of STEM careers. These three methods of raising STEM career awareness were not mutually exclusive, but often overlapped with one another.

\subsubsection{Promotion of STEM Careers through Curricula}

Eleven teachers explicitly described their implementation of integrated STEM education as a vehicle to promote students' STEM career awareness, with Antonio firmly establishing, "I think the main purpose of STEM education [is to] provoke students' interest to participate in STEM careers". Seven teachers also sparked students' awareness of STEM careers by explicitly sharing that the practices they engaged in during class simulated authentic STEM practices used by STEM practitioners. Teachers such as Allina, Jocelyn, 
and Rose talked about the benefits of using real, scientific data, allowing students to better see and understand what STEM professionals do. Rose noted, "we have to start teaching the kids how the real-world is out there because they graduate and they know nothing". Additionally, five teachers described how they incorporated STEM careers into their STEM lessons to provide context and meaning to student learning. For example, Stacy mentioned that she talked about a specific STEM career during the introduction to one of her STEM lessons, noting the connection between the career and the topic of study.

\subsubsection{Promotion of STEM Careers through Partnerships}

Ten teacher participants described events such as inviting guest speakers to their classrooms and/or establishing partnerships with organizations, universities, and companies. Clara mentioned a partnership with a local university, which she leveraged to invite college students to speak to her middle school students, who she felt they would relate to better, "And so when a college student is telling a middle school student, 'Hey, you're going to need this, you know, this is going to help you,' they kind of pay attention a little bit more". Allina noted that her students were engaged in the authentic practices of STEM professionals via partnerships, which opened a new world to students about what they could do in STEM careers. She shared, "And it's like, I think it's really important for kids to see not just, okay, we're in class with this person, and they're saying this is cool. It's like, here's the newest stuff that people are doing". Having real STEM professionals talk to students helped teachers such as Allina showcase different STEM careers in an authentic and meaningful way.

\subsubsection{Diversity-Oriented Promotion of STEM Careers}

As part of promoting STEM career awareness, four teachers focused on highlighting diversity. This was done through both curricula and partnerships, representing a crosscutting theme for implementing integrated STEM. Darma noted, "every lesson has one [STEM] career and then they all have one known Hispanic or African American showing us going in there [that career]. And then I pull up, you know, people who are other race background". She explicitly showed her students that people from diverse backgrounds could be STEM professionals. Stacy embedded some of her teaching within a global context to highlight non-white scientists in Africa working on aquaponics. Allina and Clara described how their female guest speakers engaged students in discussions related to gender equity with Clara sharing, "They incorporate a lot of young women talking about the need for women in coding, women in science, women in engineering. I really tried to include the girls and let them know that there is a need for them in the future in these areas, if they learn these skills.

Clara and Darma also mentioned how their demographic of students, which included low-socioeconomic-status students, were more engaged when guest speakers talked about chances of going to college for free when pursuing STEM degrees. Interestingly, all four teachers who addressed diversity in STEM careers were women.

\section{Discussion}

Our findings reflect much of what has previously been found in the literature related to STEM conceptions and what STEM education entails [10,14]. This is not entirely surprising given the consensus surrounding aspects such as developing skills and including realworld connections, all while encouraging student-centered pedagogies and the integration of content from multiple disciplines [14]. Additionally, since professional development can play a role in teachers' conceptions of integrated STEM education [10,21], it is also not surprising that teachers' conceptions reflected much of what they learned in their respective workshops. Because we chose not to provide a "cookbook" approach to integrated STEM education in the workshops, teachers took the framework we presented and made it their own. Most importantly, they did this with respect to the elements explored in this study as we provided no "correct" or one way to approach content integration or the content- 
agnostic elements discussed in this work. Because of this, our study adds to the literature in several ways that unpack how teachers view the contribution of each discipline within integrated STEM education, how real-world problems are used to contextualize learning, how 21st century skills are included, and how STEM careers are promoted in their classrooms. The following discussion addresses how our findings may lead to a better understanding of STEM education and how to improve professional development opportunities.

\subsection{The Multiplicity of Conceptions and Connections}

In attending to our first research question, we found that, similar to the literature [14], teachers held multiple conceptions concerning the role of each STEM discipline within integrated STEM instruction. This did not always include clear, definitive connections among the disciplines, but included multiple avenues for the disciplines to be leveraged. For instance, in some cases, technology may relate to science as a tool to collect data, but on other occasions, as a product of an engineering design task; these two conceptions do not interfere with one another but could be complementary. This reflects the ongoing tension in the literature related to technology and its place and purpose within integrated STEM education $[63,64]$, although it must be noted that teachers focused primarily on students' use of technology. Knowing that these connections were not always clear and teachers could potentially hold contrasting, yet complementary, conceptions of a given disciplines suggests that the nature of integration across disciplines may very well vary among classrooms and even across different activities or lessons. This is likely why having a clear vision of integrated STEM education when it comes to the number of disciplines and how disciplines are used has been challenging [14].

Our findings indicated that within science classrooms, mathematics and technology have been mostly relegated to supporting roles by providing a set of practices or tools for students, reflecting previous findings $[5,18]$. Despite this, our findings also suggest that teachers view these two disciplines are critical to integrated STEM education as they allow students to better understand or represent scientific ideas, help students make engineering design decisions, and assist students in developing important 21st century skills. Unlike mathematics and technology, science was viewed primarily as a knowledge base or set of facts more so than a process of learning about the world; this reflects a rather limited and positivist view of science and suggests that the content primarily being learned through integrated STEM is science. In other words, while science was something to be discovered, it was also a body of knowledge to be used by others-primarily by engineers.

Engineering was seen both as a design process to create some product and as a method to solve problems, but did not appear to include disciplinary content. The connection between these two related but separate pathways was not always clear. Engineering could be designing for the sake of design rather than designing solutions to a problem. Alternatively, engineering could provide a context for a design and a problem to solve, and additionally act as a method or process for solving that problem. In this, engineering appears to be a way to frame science teaching and provide students with something "new" and exciting to do in their class, focusing on the creation of products or projects in conjunction with learning about science concepts. This conception of engineering may reveal a rather narrow understanding, focusing primarily on the design process, that represents more of a pedagogical shift towards the inclusion of 21st century skills rather than truly incorporating another discipline into instruction.

\subsection{Content-Agnostic Characteristics: An Emphasis on the Future}

In attending to our second research question, it was no surprise that teachers viewed STEM education in the context of preparing students for their future, adult lives (Navy et al., 2021). Teachers' comments stressed the importance of equipping students with 21st century skills rather than preparing students with content knowledge, reflecting the shift in policy documents [1] that move away from rote memorization of scientific facts towards engaging students in STEM practices. This may suggest that science teachers have a clear separation 
between science teaching and integrated STEM teaching; in this, "science only" teaching may focus on content delivery and context-less laboratory investigations, versus integrated STEM teaching that focuses on a more realistic, contextualized representation of how science and STEM are used in the real-world. In this, teachers make use of real-world problems, including both local and global contexts that they believed would motivate students, similar to what has been purported in the literature [29-31]. This separation may reflect an awareness that integrated STEM is not and should not be used for all teaching as some content needs to be taught in isolation before students are ready to engage in realistic STEM practices [59].

Teachers related the need to solve problems-whether general problems or real-world problems that contextualized students learning-most readily to creativity rather than to critical thinking. Although creativity is needed in generating innovative solutions to problems, critical thinking is necessary when using data to assess how well those solutions address the problem. Generally, teacher comments about 21st century skills focused primarily on collaboration and communication, which may be "easier" or more natural to tackle in classrooms (compared to critical thinking, for example) due to their visibility and familiarity. Even though teachers emphasized the need for data analysis, teachers did not detail this process or elaborate on how they might guide students in interpreting results through critical thinking. Additionally, teachers only noted their observations of student miscommunications in group work, suggesting that they may have overlooked groups that collaborate and communicate effectively. The authors of $[65,66]$ have explored the criticality of small group tasks and the work here emphasizes the need to continue to explore this area through research, most notably to equip teachers with tools of their own to help develop these important skills.

The split in how STEM careers were promoted suggests that teachers either had not conceptualized integrated STEM education as a vehicle for promoting students' STEM career awareness or were lacking the knowledge or resources to do so. What is noteworthy is how four teachers, all women, focused on diversity when introducing STEM careers to their students. This suggests that teachers may need access to resources related to STEM careers [55], especially when it comes to diversity, to make direct connections in their curriculum and connections to those that might represent the local community. These kinds of resources can assist teachers in unpacking what diversity entails in STEM and how it can exclude or include certain groups of students from pursuing STEM-related careers. If teachers engage more in the promotion of STEM careers, especially in highlighting and encouraging diversity therein, then the STEM education community may start to actualize the promises made in policy documents to promote STEM for all $[1,3]$. This may further relate to the relevance of curriculum and the real-world problems that are selected, which should be connected to students' lives in some way for them to develop motivation and interest toward STEM [29-31].

\subsection{The Bigger Vision of Integrated STEM Education}

Our deeper dive into teachers' conceptions of integrated STEM education illuminates further complexities. For one, it is clear that the relationship between the STEM disciplines can vary, which is exacerbated by the fact that teachers conceptualize the content-agnostic characteristics in multiple ways. Even though the inclusion of 21st century skills has been prominently featured within the integrated STEM education literature, asserting what this means is unclear. Does implicitly including 4-Cs into instruction "count" or must there be explicit calls to the development of the 4-Cs? Answering this question may vary based on grade-level, which was not explored in the current work. While teachers shared their ideas and current approaches related to raising STEM career awareness, this characteristic was represented to a lesser extent. This work, while attempting to better understand teachers' current conceptions of integrated STEM education, reveals areas in which teachers may need additional support that includes expanding the role of mathematics beyond data 
analysis, informing how to explicitly address 21st century skills in their teaching, and finding resources to promote STEM career awareness.

\subsection{Limitations}

Our work is limited to the small sample size and underrepresentation of elementary teachers in particular; however, the exploratory nature of this work does not attempt to make claims about all K-12 teachers. For instance, all participants identified themselves as teachers of science, but our findings would likely be different if our focus was on mathematics or computer science teachers. While the work presented here did not include observations of teachers' implementation of integrated STEM education in their classrooms, teachers' responses provided a small window into their practice based on the conceptions they shared. There is still a need for a more thorough examination of how exactly science, technology, engineering, and mathematics are used in the classroom and to compare this to how teachers conceptualize the role of each discipline. With respect to 21st century skills, teachers acknowledged the need to develop some of these skills (primarily collaboration and communication), but it is unclear how much of this is currently done in their classrooms. We should also note that, when first asked to describe how "21st century skills" were used within their integrated STEM instruction, few teachers recognized the phrase and only when the interviewer clarified with examples of the 4-Cs did teachers provide more thorough responses.

\section{Conclusions}

This study provides valuable information related to conceptions of integrated STEM education. Additionally, this work reveals approaches in which teachers conceptualize their implementation of integrated STEM education with respect to STEM disciplines, real-world problems, 21st century skills, and promotion of STEM career awareness. Asking more pointed questions allowed us to better understand these areas so that as teacher educators, we can better support teachers. For instance, many of these teachers were new to engineering and needed support in this area; this is likely true for a large number of science teachers who are now expected to be experts in integrated STEM education. Moreover, these conceptions demonstrated a need to better understand how technology and mathematics should be included in integrated STEM education and to offer models that treat these two disciplines as more than just tools, but as a knowledge base.

Even though we asked teachers about 21st century skills and STEM careers in the context of integrated STEM education, their responses could have easily been with respect to teaching science more broadly. In this sense, these teachers better verbalized the pedagogical components of integrated STEM education than the integration of content. Focusing on pedagogy first may be a way to "ease" into shifting from science to integrated STEM teaching. Having a clear framework related to the integration of mathematics and technology beyond their supportive, tool-like and practice-based role that seems to occur in teachers' conceptions of STEM education may help to improve their integrated STEM instruction, but this is still an area in need of more attention. There is still a significant amount of work to do with respect to content integration, but studies such as the one presented here provide a clear access point to create teacher buy-in to integrated STEM education.

We make several recommendations for those working as teacher educators wishing to support science teachers as they expand their teaching to include integrated STEM. First, including teachers from multiple STEM disciplines, such as mathematics and computer science teachers, may help to further illuminate the role of mathematics and technology, as they likely have alternative understandings of integrated STEM given their teaching contexts. This may help to emphasize the different types of disciplinary integration that can happen so that mathematics and technology are not always relegated to a support role. Second, for professional development opportunities, there is a need for clearer and more explicit connections to 21st century skills and STEM careers within integrated STEM frameworks. This could come in the form of some supplemental PD to enhance one focused 
on the nature of STEM integration. In particular, an emphasis should be placed on the diversity of STEM professionals, not just focusing on those who are most often cited in school textbooks (e.g., Albert Einstein) that ignore historically underrepresented groups. Further, this PD could promote diversity through an empathic lens by helping teachers understand the barriers and struggles that these marginalized groups overcome before and after becoming STEM professionals. Third, teachers should also be regularly faced with articulating their STEM conception model and challenged to describe the intricacies. The disconnection between the promotion of STEM career awareness and integrated STEM curricula suggests that the integrated STEM education PD should empower teachers with the ideas and practical capability to promote students' STEM career awareness through integrated STEM lessons, especially as related to diversity within STEM careers. Further, these attempts should motivate students to pursue more STEM-related courses and seriously consider STEM careers. Finally, outside of professional development, there is a need to continue to support teachers during the implementation phases and allow them frequent opportunities to reflect on their practice. Simultaneously, as researchers, we need to closely examine how integrated STEM education plays out in classrooms and examine how these aspects are implemented.

Author Contributions: All authors conceptualized and designed the study based on previous work. K.K., B.M.H. and F.L. collected and organized all data. All authors participated in data analysis and initial draft of the manuscript. E.A.D. led revisions and final format of the manuscript. All authors have read and agreed to the published version of the manuscript.

Funding: This study was made possible by NSF grant \#1854801, 1813342, and 1812794. The findings, conclusions, and opinions herein represent the views of the authors and do not necessarily represent the view of personnel affiliated with the National Science Foundation.

Informed Consent Statement: Informed consent was obtained from all subjects involved in the study.

Data Availability Statement: Due to IRB permissions, data cannot be shared outside of those directly related to the project.

Conflicts of Interest: The authors declare no conflict of interest.

\section{References}

1. National Research Council. A Framework for K-12 Science Education: Practices, Crosscutting Concepts, and Core Ideas; The National Academies Press: Washington, DC, USA, 2012.

2. NGSS Lead States. Next Generation Science Standards: For States, by States; The National Academies Press: Washington, DC, USA, 2013.

3. National Research Council. Successful K-12 STEM Education: Identifying Effective Approaches in Science, Technology, Engineering, and Mathematics; The National Academies Press: Washington, DC, USA, 2011.

4. National Research Council. Monitoring Progress toward Successful K-12 STEM Education: A Nation Advancing? The National Academies Press: Washington, DC, USA, 2013.

5. Dare, E.A.; Ring-Whalen, E.A.; Roehrig, G.H. Creating a continuum of STEM models: Exploring how K-12 science teachers conceptualize STEM education. Int. J. Sci. Educ. 2019, 41, 112-144. [CrossRef]

6. Breiner, J.M.; Harkness, S.S.; Johnson, C.C.; Koehler, C.M. What is STEM? A discussion about conceptions of STEM in education and partnerships. Sch. Sci. Math 2012, 112, 3-11.

7. Bybee, R.W. Advancing STEM education: A 2020 vision. Tech. Eng. Teach. 2010, 70, 30-35.

8. Martín-Páez, T.; Aguilera, D.; Perales-Palacios, F.J.; Vílchez-González, J.M. What are we talking about when we talk about STEM education? A review of literature. Sci. Educ. 2019, 103, 799-822.

9. Navy, S.L.; Kaya, F.; Boone, B.; Brewster, C.; Calvelage, K.; Ferdous, T.; Hood, E.; Sass, L.; Zimmerman, M. “Beyond an acronym, STEM is ... ": Perceptions of STEM. Sch. Sci. Math 2021, 121, 36-45. [CrossRef]

10. Ring-Whalen, E.A.; Dare, E.A.; Roehrig, G.H.; Titu, P.; Crotty, E.A. From conception to curricula: The role of science, technology, engineering, and mathematics in integrated STEM units. Int. J. Educ. Math. Sci. Technol. 2018, 6, 343-362. [CrossRef]

11. Bartels, S.L.; Rupe, K.M.; Lederman, J.S. Shaping preservice teachers' understandings of STEM: A collaborative math and science methods approach. J. Sci. Teach. Educ. 2019, 30, 666-680. [CrossRef]

12. Radloff, J.; Guzey, S. Investigating preservice STEM teacher conceptions of STEM education. J. Sci. Educ. Tech. 2016, 25, 759-774. [CrossRef] 
13. Roehrig, G.H.; Dare, E.A.; Ellis, J.A.; Ring-Whalen, E.A. Beyond the Basics: A Detailed Conceptual Framework of Integrated STEM. Disc. Interdisc. Sci. Ed. Rsch. 2021. Forthcoming.

14. Moore, T.J.; Johnston, A.C.; Glancy, A.W. STEM integration: A synthesis of conceptual frameworks and definitions. In Handbook of Research on STEM Education; Johnson, C.C., Mohr-Schroeder, M.J., Moore, T.J., English, L.D., Eds.; Routledge: London, UK, 2020; pp. 3-16.

15. National Academy of Engineering and National Research Council. STEM Integration in K-12 Education: Status, Prospects, and an Agenda for Research; The National Academies Press: Washington, DC, USA, 2014.

16. Gow, L.; Kember, D. Conceptions of teaching and their relationship to student learning. Br. J. Educ. Psychol. 1993, 63, 20-33. [CrossRef]

17. Trigwell, K.; Prosser, M.; Waterhouse, F. Relations between teachers' approaches to teaching and students' approaches to learning. High. Educ. 1999, 37, 57-70. [CrossRef]

18. Ring, E.A.; Dare, E.A.; Crotty, E.A.; Roehrig, G.H. The evolution of teacher conceptions of STEM education throughout an intensive professional development experience. J. Sci. Teach. Educ. 2017, 28, 444-467. [CrossRef]

19. Luft, J.A.; Diamond, J.M.; Zhang, C.; White, D.Y. Research on K-12 STEM professional development programs: An examination of program design and teacher knowledge and practice. In Handbook of Research on STEM Education; Johnson, C.C., Mohr-Schroeder, M.J., Moore, T.J., English, L.D., Eds.; Routledge: London, UK, 2020; pp. 361-374.

20. Dare, E.A.; Ellis, J.A.; Roehrig, G.H. Understanding science teachers' implementations of integrated STEM curricular units through a phenomenological multiple case study. Int. J. STEM Educ. 2018, 5, 1-19. [CrossRef]

21. Du, W.; Liu, D.; Johnson, C.C.; Sondergeld, T.A.; Bolshakova, V.L.J.; Moore, T.J. The impact of integrated STEM professional development on teacher quality. Sch. Sci. Math. 2019, 119, 105-114. [CrossRef]

22. Johnson, C.C.; Sondergeld, T.A. Effective STEM professional development. In STEM Road Map: A Framework for Integrated STEM Education; Johnson, C.C., Peters-Burton, E.E., Moore, T.J., Eds.; NSTA Press: Arlington, VA, USA, 2015; pp. $203-210$.

23. Shernoff, D.J.; Sinha, S.; Bressler, D.M.; Ginsburg, L. Assessing teacher education and professional development needs for the implementation of integrated approaches to STEM education. Intnl. J. STEM Educ. 2017, 4, 13. [CrossRef]

24. Wang, H.-H.; Moore, T.J.; Roehrig, G.H.; Park, M.S. STEM integration: Teacher perceptions and practice. J. Pre-College Eng. Educ. Rsch. 2011, 1, 1-13.

25. Hill, C.; Corbett, C.; St. Rose, A. Why So Few? Women in Science, Technology, Engineering, and Mathematics; AAUW: Washington, DC, USA, 2010.

26. Vakil, S.; Ayers, R. The racial politics of STEM education in the USA: Interrogations and explorations. Race Ethn. Educ. 2019, 22, 449-458. [CrossRef]

27. Lachapelle, C.; Cunningham, C. Engineering in elementary schools. In Engineering in Pre-College Settings: Synthesizing Research, Policy, and Practices; Purzer, S., Strobel, J., Cardella, M., Eds.; Purdue University Press: West Lafayette, IN, USA, 2014; pp. 61-88.

28. Monson, D.; Besser, D. Smashing milk cartons: Third-grade students solve a real-world problem using the engineering design process, collaborative group work, and integrated STEM education. Sci. Child. 2015, 52, 38-43. [CrossRef]

29. Djonko-Moore, C.; Leonard, J.; Holifield, Q.; Bailey, E.; Almughyirah, S. Using culturally relevant experiential education to enhance urban children's knowledge and engagement in science. J. Experiential. Educ. 2018, 41, 137-153. [CrossRef]

30. Moll, L.C.; Amanti, C.; Neff, D.; Gonzalez, N. Funds of knowledge for teaching: Using a qualitative approach to connect homes and classrooms. Theory Into Pract. 1992, 31, 132-141. [CrossRef]

31. Upadhyay, B.R. Using students' lived experiences in an urban science classroom: An elementary school teacher's thinking. Sci. Educ. 2005, 90, 94-110. [CrossRef]

32. Science and Engineering Indicators 2020: The State of U.S. Science and Engineering (NSB-2020-1). Available online: https: / / ncses.nsf.gov/pubs/nsb20201/ (accessed on 1 June 2021).

33. Partnership's Web Site. A State leader's Action Guide to 21st Century Skills: A New Vision for Education; Partnership for 21st Century Skills: Tucson, AZ, USA, 2006. Available online: http://apcrsi.pt/website/wp-content/uploads/20170317_Partnership_for_21 st_Century_Learning.pdf (accessed on 10 November 2021).

34. Bellanca, J.; Brandt, R. 21st Century Skills: Rethinking How Students Learn; Solution Tree Press: Bloomington, IN, USA, 2010.

35. Stehle, S.M.; Peters-Burton, E.E. Developing student 21st Century skills in selected exemplary inclusive STEM high schools. Int. J. STEM Educ. 2019, 6, 39. [CrossRef]

36. Trilling, B.; Fadel, C. 21st Century Skills: Learning for Life in Our Times; Jossey-Bass: Hoboken, NJ, USA, 2009.

37. Bybee, R.W. A Case for STEM Education; NSTA Press: Arlington, VA, USA, 2013.

38. Johnson, C.E.; Peters-Burton, E.E.; Moore, T.J. STEM Road Map: A Framework for Integrated STEM Education; Routledge: London, UK, 2016.

39. National Education Association. Preparing 21st Century Students for a Global Society: An Educator's Guide to the "Four Cs"; National Education Association: Washington, DC, USA, 2012.

40. Cox, C.B. 21st Century Skills and Principles of Flow in the Foreign Language Classroom (Publication No, 4197). Master's Thesis, Brigham Young University, Provo, UT, USA, 2014.

41. Hughes, C. Theory of Knowledge aims, objectives and assessment criteria: An analysis of critical thinking descriptors. J. Rsch. Intnl. Educ. 2014, 13, 30-45. [CrossRef]

42. Browne, M.; Keeley, S. Asking the Right Questions: A Guide to Critical Thinking, 6th ed.; Prentice Hall: Hoboken, NJ, USA, 2001. 
43. Mednick, S. The associative basis of the creative process. Psyc. Rev. 1962, 69, 220-232. [CrossRef]

44. Finke, R.A.; Ward, T.B.; Smith, S.M. Creative Cognition: Theory, Research and Applications; MIT Press: Cambridge, MA, USA, 1992.

45. Carpenter, J.P.; Pease, J.S. Preparing students to take responsibility for learning: The role of non-curricular learning strategies. J. Curric. Instr. 2013, 7, 38-55. [CrossRef]

46. Jonassen, D.; Strobel, J.; Lee, C.B. Everyday problem solving in engineering: Lessons for engineering educators. J. Eng. Educ. 2006, 95, 139-151. [CrossRef]

47. North Central Regional Educational Laboratory \& Group. EnGauge 21st Century Skills: Literacy in Digital Age; North Central Regional Educational Laboratory: Naperville, IL, USA, 2003.

48. Husin, W.; Fadzilah, W.N.; Arsad, M.; Nurazidawati, O.; Oziah, H.; Lilia, R.; Sattar, M.; Osman, K.; Iksan, Z. Fostering students' 21st century skills through project oriented problem based learning (POPBL) in integrated STEM education program. Asia-Pac. Forum Sci. Learn. Teach. 2016, 17, 1-18.

49. President's Council of Advisors on Science and Technology (PCAST). Prepare and Inspire: K-12 Education in Science, Technology, Engineering and Math (STEM) for America's Future. 2010. Available online: http://www.whitehouse.gov/sites/default/files/ microsites/ostp/pcaststemed-report.pdf (accessed on 1 May 2021).

50. Barth, J.M.; Masters, S. Changes in math and science interest over school transitions: Relations to classroom quality, gender stereotypes, and efficacy. Intnl. J. Gend. Sci. Tech. 2020, 12, 4-31.

51. Xie, Y.; Fang, M.; Shauman, K. STEM education. Annu. Rev. Sociol. 2015, 41, 331-357. [CrossRef]

52. Johnson, A.; Elliott, S. Culturally relevant pedagogy: A model to guide cultural transformation in STEM departments. J. Microbiol. Biol. Educ. 2020, 21, 5. [CrossRef]

53. Hazari, Z.; Sadler, P.M.; Sonnert, G. The science identity of college students: Exploring the intersection of gender, race, and ethnicity. J. Coll. Sci. Teach. 2013, 42, 82-91.

54. Upadhyay, B.; Atwood, E.; Tharu, B. Actions for sociopolitical consciousness in a high school science class: A case study of ninth grade class with predominantly indigenous students. J. Rsch. Sci. Teach. 2020, 57, 1119-1147. [CrossRef]

55. Cohen, C.; Patterson, D.G.; Kovarik, D.N.; Chowning, J.T. Fostering STEM career awareness: Emerging opportunities for teachers. Wash. State Kappan 2013, 6, 12-17.

56. Knowles, J.G.; Kelley, T.R.; Holland, J.D. Increasing teacher awareness of STEM careers. J. STEM Educ. 2018, 19, 47-55.

57. Merriam, S.B. Qualitative Research and Case Study Applications in Education: Revised and Expanded from Case Study Research in Education; Jossey-Bass Publishers: Hoboken, NJ, USA, 1998.

58. Mills, A.J.; Durepos, G.; Wiebe, E. (Eds.) Encyclopedia of Case Study Research; SAGE: Thousand Oaks, CA, USA, 2009.

59. Kelley, T.R.; Knowles, J.G. A conceptual framework for integrated STEM education. Intnl. J. STEM Educ. 2016, 3, 2-11. [CrossRef]

60. Dare, E.A.; Ring-Whalen, E.A. Eliciting and refining conceptions of STEM education: A series of activities of professional development. Innov. Sci. Teach. Educ. 2021, 6, 1-19.

61. Corbin, J.; Strauss, A. Basics of Qualitative Research, 4th ed.; SAGE: Thousand Oaks, CA, USA, 2015.

62. Miles, M.B.; Huberman, A.M.; Saldaña, J. Qualitative Data Analysis: A Methods Sourcebook, 4th ed.; SAGE: Thousand Oaks, CA, USA, 2019.

63. Ellis, J.A.; Wieselmann, J.R.; Sivaraj, R.; Roehrig, G.H.; Dare, E.A.; Ring-Whalen, E.A. Toward a productive definition of technology in science and STEM education. Contemp. Issues in Tech. and Teach. Educ. 2020, 20, 472-496.

64. Cullen, T.; Guo, M. The nature of technology. In Critical Questions in STEM Education; Akerson, V.L., Buck, G.A., Eds.; Springer: New York, NY, USA, 2020; pp. 21-32.

65. Wieselmann, J.R.; Dare, E.A.; Ring-Whalen, E.A.; Roehrig, G.H. "I just do what the boys tell me": Exploring small group student interactions in an integrated STEM unit. J. Rsch. Sci. Teach. 2020, 57, 112-144. [CrossRef]

66. Wieselmann, J.R.; Dare, E.A.; Ring-Whalen, E.A.; Roehrig, G.H. "There are other ways to help besides using the stuff": Using activity theory to understand dynamic student participation in small group activities. J. Rsch. Sci. Teach. 2021, 58, 1281-1319. [CrossRef] 